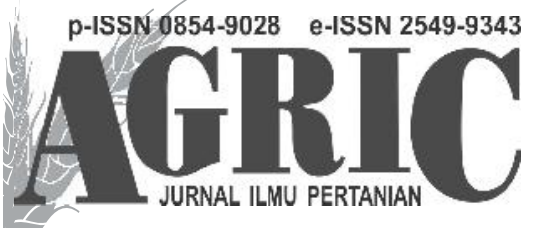

Fakultas Pertanian dan Bisnis Universitas Kristen Satya Wacana

Jl. Diponegoro 52-60 SALATIGA 50711 - Telp. 0298-321212 ext 354

email: jurnal.agric@adm.uksw.edu, website: ejournal.uksw.edu/agric

PENGARUH METODE APLIKASI AZOTOBACTER TERHADAP HASIL KEDELAI (GLYCINE MAX (L.) MERILL) DI LAHAN KERING

\title{
EFFECT OF AZOTOBACTER APPLICATION METHOD ON YIELD OF SOYBEAN (GLYCINE MAX (L.) MERILL) ON DRY LAND
}

\author{
Reginawanti Hindersah ${ }^{1}$, Rara Rahmatika Risanti ${ }^{1}$, Ibnu Haikal ${ }^{1}$, Yuliati Mahfud ${ }^{1}$, Nenny \\ Nurlaeny ${ }^{1}$, Meddy Rachmadi ${ }^{2}$ \\ ${ }^{1}$ Departemen Ilmu Tanah Fakultas Pertanian Universitas Padjadjaran \\ Jalan Raya Bandung-Sumedang Km. 21 Jatinangor, Sumedang 45363 \\ ${ }^{2}$ Departemen Agronomi Fakultas Pertanian Universitas Padjadjaran \\ E-mail: reginawanti@unpad.ac.id
}

Diterima: 1 Mei 2019, disetujui 13 Desember 2019

\section{ABSTRACT}

Biofertilizer which contain rhizobacteria Azotobacter increase soil fertility and improve plant growth through nitrogen fixation and phytohormone production. The objective of this study was to compare the responses of soybean (Glycine max (L.) Merill) plants in dry land after the application of several Azotobacter inoculation methods. Field experiments were carried out with a randomized block design consisting of five treatments with five replicates each. The treatments were seed inoculation, soil treatment before planting, soil treatment after planting and plant dressing. Plant inoculation with Azotobacter treated with half of recommended dosage urea while the control plant received recommended dose urea. The experimental results showed that all application methods did not affect soybean production, number of nodules, Azotobacter populations in the rhizosphere and $N$ total soil; but influenced $N$ uptake and soybean seeds weight. The results suggested that best inoculation method was by spraying on the leaves. This experiment explained that all Azotobacter application methods did not increase soybean cv Arjasari yield but plant dressing method might be suggested since it increased nitrogen uptake and weight of 100 soybean seeds

Keywords: Azotobacter, Nodule, Nitrogen, Biofertilizer 


\begin{abstract}
ABSTRAK
Pupuk hayati dengan bahan aktif rizobakteri Azotobacter mampu meningkatkan kesuburan tanah dan meningkatkan pertumbuhan tanaman melalui fiksasi nitrogen dan produksi fitohormon. Tujuan penelitian ini adalah membandingkan respons tanaman kedelai (Glycine max (L.) Merill) di lahan kering setelah aplikasi beberapa metode inokulasi Azotobacter. Percobaan lapangan dilakukan dengan Rancangan Acak Kelompok yang terdiri atas lima perlakuan dan lima ulangan. Perlakuan yang diuji adalah inokulasi Azotobacter melalui benih, tanah sebelum tanam, tanah setelah tanam dan tajuk tanaman. Pertamanan dengan inokulasi Azotobacter diberi pupuk urea $50 \%$ dari dosis rekomendasi sedangkan tanaman kontrol mendapatkan urea dosis rekomendasi. Hasil percobaan menunjukkan bahwa seluruh metode aplikasi tidak mempengaruhi produksi kedelai, jumlah nodula, populasi Azotobacter di rizosfer dan $\mathrm{N}$ total tanah; tetapi berpengaruh terhadap serapan $\mathrm{N}$ dan bobot biji kedelai. Penelitian ini menjelaskan bahwa seluruh metode aplikasi Azotobacter tidak meningkatkan hasil kedelai cv. Arjasari tetapi inokulas dengan metode penyemprotan pada daun dapat disarankan karena meningkatkan serapan nitrogen dan bobot 100 biji kedelai.
\end{abstract}

Kata Kunci: Kata kunci: Azotobacter, Nodula, Nitrogen, Pupuk Hayati

\section{PENDAHULUAN}

Permintaan kedelai terus meningkat, namun tidak diimbangi oleh produksi dalam negeri. Produktivitas nasional kedelai adalah sekitar 1,5 t/ha untuk menghasilkan kedelai sebanyak 859.653 ton pada 2016 dan 538.728 ton pada tahun 2017 (Kementrian Pertanian, 2017); lebih rendah daripada tahun 2015 (Badan Pusat Statistik, 2015) yang mencapai 963.183 ton. Oleh karena itu, industri pengolahan kedelai tergantung kepada kedelai impor.

Ekstensifikasi kedelai banyak dilakukan di lahan kering dengan tanah ordo Inceptisols yang luasnya mencapai sekitar 70,5 juta ha atau $37,5 \%$ dari total luas daratan Indonesia (Pusat Penelitian Tanah dan Agroklimat, 2000). Ineptisols memiliki tingkat kesuburan rendah dan masam meskipun sifat fisik baik (Abdurachman et al., 2008). Kendala ketersediaan nutrisi nitrogen $(\mathrm{N})$ di Ineptisols umumnya diatasi dengan pupuk anorganik. Pada pertanian berkelanjutan, pemupukan berimbang yang terdiri atas pupuk organik, anorganik dan pupuk hayati dianjurkan.
Kedelai bersimbiosis dengan Bradyrhizobium pada bintil akar yang penting untuk penyediaan N. Aplikasi pupuk hayati Rhizobium/ Bradyrhizobium telah banyak dilakukan di pertanaman kedelai untuk mengoptimalkan aktivitas fiksasi nitrogen, dan mempertahankan ataupun meningkatkan hasil tanaman (Ntambo et al., 2017; Adeyeye et al., 2017). Inokulasi ganda B. japonicum dengan Azotobacter pada kondisi rumah kaca telah dilaporkan dapat meningkatkan nodulasi, serapan unsur hara $\mathrm{N}$ serta produksi kedelai (Koziel et al. , 2013; Sara et al., 2014).

Azotobacter adalah rizobakteri pemfiksasi nitrogen hidup bebas, penghasil fitohormon (kukreja et al., 2004); serta eksopolisakarida (EPS) yang terdiri atas asam organik dan polisakarida (Gauri et al., 2012; Hindersah et al., 2015). Azotobacter akan memberikan keuntungan terhadap perkembangan akar dan imobilisasi Rhizobium di rizosfer yang menginduksi pembentukan nodula serta kualitas hasil tanaman dan peningkatan serapan $\mathrm{N}$ kedelai (Burns et al., 1981). 
Efektivitas pupuk hayati Azotobacter dapat ditingkatkan dengan metode aplikasi yang tepat baik melalui benih, daun mapun tanah. Namun metode aplikasi akan berbeda untuk setiap tanaman. Inokulasi pupuk hayati yang efektif dan efisien dapat dilakukan melalui perlakuan benih (Sharma et al., 2014). Pada tanaman anggur pengaruh aplikasi pupuk hayati melalui daun meningkatkan bobot tandan buah dan ukuran buah tetapi tidak mempengaruhi kualitas (Nagy dan Pinter, 2015).

Penelitian metode aplikasi inokulan cair Azotobacter pada pertanaman kedelai di lahan belum banyak. Belum ada informasi mengenai respons tanaman kedelai dan juga hasilnya akibat perbedaan metode inokulasi. Penelitian ini penting dilakukan karena program swasembadakedelai Kementrian Pertanian RI mengarah pada ekstensifikasi di lahan masam seperti Inceptisols. Tujuan penelitian lapangan ini adalah membandingkan respons tanaman terutama nodulasi dan serapan $\mathrm{N}$ serta produksi kedelai setelah aplikasi Azotobacter melalui benih (seed dressing), tanah (top dressing) dan tajuk tanaman (foliar dressing).

\section{METODE PENELITIAN}

Penelitian exprimental dilaksanakan pada JuliNovember 2015 di kebun percobaan Fakultas Pertanian Universitas Padjadjaran, Kecamatan Jatinangor, Kabupaten Sumedang, pada ketinggian 765 meter di atas permukaan laut. Tanah di lahan percobaan adalah Inceptisols dengan $\mathrm{pH} 5,8$, bertekstur liat dengan kesuburan tanah rendah. Inceptisols mengandung $\mathrm{C}$ organik rendah $1,58 \%$, $\mathrm{N}$-total rendah $0,2 \%$, $\mathrm{CN} 8, \mathrm{P}_{2} \mathrm{O}_{5}$ dan $\mathrm{K}_{2} \mathrm{O}$ total rendah masing- masing $14,27 \mathrm{mg} / 100 \mathrm{~g}$ dan $19,02 \mathrm{mg} / 100 \mathrm{~g}$, Kapasitas Tukar Kation tanah dan Kejenuhan Basa sedang masing-masing 21,7 cmol/ $\mathrm{kg}^{-1}$ dan $56,6 \%$ sedang. Benih Kedelai cv. Arjasari jenis determinate (pertumbuhan terhenti setelah tanaman berbunga) adalah koleksi Program Studi Pemuliaan Tanaman Fakultas Pertanian. Bakteri Azotobacter sp. dan Bradyrhizobium diisolasi dari rizosfer kedelai yang diperoleh dari Balai Penelitian Tanaman Kacang dan Umbi Malang.

\section{Rancangan Percobaan}

Percobaan lapangan menggunakan Rancangan Acak Kelompok dengan lima perlakuan metode aplikasi pupuk hayati Azotobacter adalah:

\section{Kontrol, tanpa Azotobacter}

Inokulasi ke benih dengan dosis $3 \mathrm{~L} / \mathrm{ha}$

Inokulasi ke tanah sebelum tanam dengan dosis $3 \mathrm{~L} / \mathrm{ha}$

Inokulasi ke tanah setelah tanam dengan dosis $6 \mathrm{~L} / \mathrm{ha}$ (3 dan 4 MST)

Inokulasi ke tajuk tanaman dengan dosis 6 L/ha (3 dan 4 MST)

Seluruh perlakuan diulang limakali dan di setiap petak terdapat 100 lubang tanam. Tanaman dipelihara sampai panen, parameter yang diamati terdiri atas 1) tinggi tanaman pada 5 MST, 2) jumlah nodula akar per tanaman pada saat vegetatif maksimum (5 MST), 3) Serapan $\mathrm{N}$ tanaman kedelai pada saat vegetatif maksimum (5 MST), 4) Bobot per 100 biji dan bobot kering udara biji kedelai per petak.

Seluruh data dianalisis dengan analisis ragam, uji F pada taraf kepercayaan 95\%, jika terdapat perbedaan nyata efek perlakuan terhadap 
parameter yang diukur maka dilakukan Uji Jarak Berganda Duncan pada taraf kepercayaan $95 \%$.

\section{Pelaksanaan Percobaan}

Pengolahan tanah dilakukan dengan cangkul sedalam $25 \mathrm{~cm}$, kemudian di atas lahan dibuat 5 petak dengan 5 ulangan yang memanjang dari arah utara-selatan. Parit selebar $50 \mathrm{~cm}$ dan sedalam $25 \mathrm{~cm}$ dibuat di antara petak dan di sekelilng lahan. Tanah sedalam $20 \mathrm{~cm}$ di setiap petak dicampur dengan 2 ton/ha kotoran sapi (1,5 kg/petak) dan diinkubasi satu minggu. Kotoran sapi mengandung C-organik 33,5\%, $\mathrm{C} / \mathrm{N} 18, \mathrm{~N}$ total 1,8\%, P 1,2\% dan K 3,71\%.

Benih kedelai untuk seluruh perlakuan kecuali kontrol dan inokulasi benih direndam dengan inokulan Bradyrhizobium kepadatan $10^{6} \mathrm{CFU} /$ mL yang dicampur dengan gum arabic $1 \%$ (b/ v). Dua benih kedelai cv. Arjasari dengan daya kecambah $95 \%$ ditanam di dalam tugalan dengan kedalaman $3 \mathrm{~cm}$ pada jarak tanam 15 cm di dalam bedengan; penjarangan pada saat 2 MST menyisakan satu tanaman terbaik yang dipelihara sampai masa panen.

Pupuk hayati Azotobacter diaplikasikan sesuai dengan metode perlakuan yang diberikan. Inokulasi benih dilakukan dengan merendam benih kedelai di dalam inokulan cair mengandung Azotobacter sp. dan Bradyrhizobium dengan kepadatan $10^{6} \mathrm{CFU} / \mathrm{mL}$ yang ditambah dengan gum arabic $1 \%(\mathrm{~b} / \mathrm{v})$. Inokulasi pada tanah menggunakan inokulan cair sebanyak $3 \mathrm{~L} / \mathrm{ha}$ dengan kepadatan sel $10^{8} \mathrm{CFU} / \mathrm{mL}$ pada kadar $5 \%$; inokulan dicampurkan bersama dengan pupuk organik saat persiapan lahan. Inokulasi pada tanah setelah tanam dilakukan dengan menyiramkan inokulan Azotobacter ke sekitar perakaran tanaman pada 3 dan $4 \mathrm{MST}$ dengan dosis $6 \mathrm{~L} \mathrm{ha}^{-1}$ pada kadar 5\%. Inokulasi pada daun dilakukan dengan menyemprotkan inokulan cair Azotobacter sp. ke permukaan daun kedelai pada 3 dan 4 MST dengan dosis $6 \mathrm{~L} /$ ha pada kadar $5 \%$.

Pupuk urea diberikan setengah dosis perlakuan sebanyak $37,5 \mathrm{~kg} \mathrm{ha}^{-1}$ pada saat tanaman berumur 2 MST; petak kontrol mendapatkan $100 \%$ pupuk urea sebanyak $75 \mathrm{~kg} / \mathrm{ha}$. Pupuk SP-36 dan $\mathrm{KCl}$ dosis rekomendasi masingmasing $100 \mathrm{~kg} /$ ha diaplikasikan pada 2 minggu setelah tanam (MST) dan 4 MST. Serangan hama ulat penggulung daun (Omides inidicate) mencapai $10 \%$ dari seluruh total tanaman sehingga dilakukan penyemprotan pestisida dengan bahan aktif deltrametrin $25 \mathrm{~g} / \mathrm{L}$. Penyemprotan ke seluruh bagian tanaman dilakukan pada saat 7 MST dan 14 MST dengan konsentrasi $0,1 \%$. Pestisida dengan bahan aktif yang sama disemprotkan untuk mengendalikan hama lalat buah, belalang, dan thrips pada saat tanaman mulai berpolong (7 MST) dan 3 minggu setelahnya (10 MST).

Sampel untuk analisis nodula, populasi Azotobacter di rizosfer; serta kadar N tanah dan tajuk diambil dari lima titik sampel acak yang digabungkan menjadi sampel komposit. Nodula efektif yang berwarna merah muda dihitung dari seluruh bagian akar. Tanah rizosfer dikoleksi dari tanah di permukaan akar setelah akar dikibaskan untuk menghilangkan bongkahan tanah. Sampel tanah untuk analisis $\mathrm{N}$ diambil dari dua titik pada jarak $3 \mathrm{~cm}$ dari batang kedelai, dikeringanginkan dan dianalisis dengan metode Kjeldahl. Tajuk tanaman dikeringkan sampai bobot konstan pada $60^{\circ} \mathrm{C}$ 
sebelum kadar $\mathrm{N}$ tajuk dianalisis dengan metode Kjeldahl. Umur panen tanaman kedelai cv. Arjasari adalah sekitar 100 hari; panen polong kedelai dilakukan secara bertahap mulai 98 hari sampai 103 hari. Polong dikeringkan dan dijemur sampai 3 hari sebelum berat polong ditimbang.

\section{HASIL DAN PEMBAHASAN}

Percobaan dilakukan pada musim kemarau dan hujan tidak turun sama sekali pada Juli sampai September. Curah hujan di bulan Oktober dan November hanya masing-masing $0,3 \mathrm{~mm}$ dan $5,1 \mathrm{~mm}$. Tanaman disiram setiap hari tetapi pertumbuhan tetap terhambat dan tanah kering sehingga perkembangan akar serabut (lateral) di menjadi terhambat. Di akhir fase vegetatif, akar serabut kedelai pada percobaan ini tidak sebanyak akar kedelai normal (Gambar 1). Akibatnya, tinggi tanaman pada 6 MST di akhir fase vegetatif pada saat mulai berbunga hanya sekitar $20 \mathrm{~cm}$ padahal tinggi kedelai cv Arjasari dapat mencapai $72 \mathrm{~cm}$.
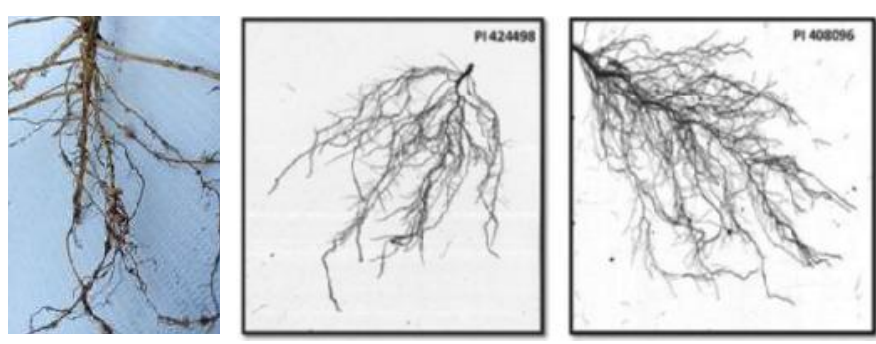

Gambar 1 Arsitektur akar kedelai di fase vegetatif akhir (kiri) tidak seintensif kedelai pada umumnya (kanan). Sumber gambar kanan: Prince et al., 2019

Perlakuan metode aplikasi Azotobacter tidak memengaruhi jumlah nodula, populasi Azotobacter maupun $\mathrm{N}$ total tanah tetapi meningkatkan serapan $\mathrm{N}$ di tajuk tanaman (Tabel 1). Pembentukan bintil akar merepresentasikan interaksi antara bakteri $\mathrm{N}$ simbiotik rizobia dengan akar tanaman. Jumlah nodula pada semua perlakuan dalam percobaan hanya 4-6 buah. Faktor pembentukan nodula terutama tergantung dari kadar $\mathrm{N}$ di tanah (Xia et al., 2017); kemasaman, kelembaban dan suhu tanah (Al Falih, 2002); serta inokulasi Bradyrhizobium (Bhuiyan et al., 2008).

Nitrogen total di tanah setelah percobaan (Tabel 1) termasuk rendah yang mendukung pembentukan nodula (Xia et al., 2017). Suhu dan kelembaban tanah selama penelitian tidak diukur namun kekeringan dapat meningkatkan suhu dan menurunkan kelembaban yang menurunkan nodulasi (Al Falih, 2002). kekeringan menghambat proliferasiAzotobacter dan rizobia serta infeksi rizobia ke akar. Rendahnya jumlah nodula juga disebabkan oleh strain Bradyrhizobum yang diinokulasikan tidak resistens terhadap kekeringan. Penelitian kedelai di Indonesia memperlihatkan jumlah nodula per tanaman adalah antara 2-78 (Lestari dan Harsono, 2017); Kumalasari et al., 2013; Meitasari dan Wicaksono, 2017) tergantung dari perlakuan pemupukan. Suatu penelitian di rumah kaca bahkan memperlihatkan nodul akar kedelai yang hanya berjumlah $<8$ pada berbagai perlakuan pemupukan organik maupun hayati (Lestari dan Harsono, 2017).

Inokulasi Azotobacter tidak memengaruhi populasinya di rizosfer kedelai meskipun Populasi Azotobacter di tanah meningkat daripada sebelum percobaan $10^{4}$ CFU/g. Peningkatan populasi bakteri karena adanya eksudat yang dilepaskan akar dan menjadi sumber nutrisi bakteri (Dennis et al., 2010). Nitrogen total tanah adalah $0,18-0,21 \%$ 
tidak berbeda dengan sebelum percobaan yaitu 0,2\%. Seluruh metode inokulasi Azotobacter tidak menambah $\mathrm{N}$ tanah seperti yang diharapkan padahal kadar $\mathrm{N}$ tanah rendah. Hal ini diduga karena fiksasi nitrogen oleh Azotobacter mungkin tidak intensif karena dibatasi oleh kekeringan yang menyebabkan terhambatnya penyediaan energi untuk fiksasi nitrogen yang berasal dari bahan organik tanah.

Seluruh tanaman diinokulasi dengan Bradyrhizobium tetapi inokulasi ganda dengan Azotobacter melalui daun meningkatkan serapan N (Tabel 1). Azotobacter memproduksi hormon auksin, sitokinin dan giberelin (Kukreja et al., 2004); aplikasi inokulan cair melalui daun memudahkan hormon diserap oleh tanaman dan meningkatkan perakaran untuk menyerap $\mathrm{N}$.

Metode aplikasi tidak mempengaruhi hasil meskipun secara nominal terdapat bobot kedelai per petak setelah aplikasi Azotobacter (Tabel2). Tanaman hanya mengandung sedikit nodula (Tabel 1) sehingga urea akan berperan penting dalam pertumbuhan vegetatif yang selanjutnya akan memperbanyak cabang penghasil polong.

Pada petak dengan inokulasi, penyakit rebah kecambah yang disebabkan oleh Phytium spp. menyerang terutama petak dengan inkulasi daun dan inokulasi tanah segera setelah kedelai berkecambah. Phytium spp. mematikan tanaman sehingga populasi tanaman menurun sampai $15 \%$ dan berpenaruh terhadap hasil (Lamichhane et al., 2017). Namun Inokulasi Azotobacter melalui daun dengan nyata meningkatkan kualitas hasil yang diperlihatkan oleh meningkatknya bobot 100 biji (Tabel 2). Azotobacter menghasilkan N; aplikasi melalui daun meningkatkan serapan $\mathrm{N}$ tanaman (Tabel 1) yang berperan meningkatkan luas daun. Perkembangan area daun selain ditentukan oleh alokasi karbon juga tergantung dari serapan $\mathrm{N}$ (Gastal and Lemaire, 2002). Luas area daun tidak diukur pada percobaan ini tetapi (Suroso dan Sodik, 2016) menjelaskan bahwa pada percobaan lapangan, bobot biji kedelai berbanding lurus dengan luas daun.

Hasil perocbaan lapangan ini kurang sejalan dengan hasil peneliti lain di rumah kaca. Tinggi

Tabel 1 Pengaruh metode inokulasi Azotobacter terhadap jumlah nodula, populasi Azotobacter di rizosfer, nitrogen total tanah dan serapan nitrogen tajuk kedelai pada 5 minggu setelah tanam

\begin{tabular}{lcccc}
\hline \multicolumn{1}{c}{ Metode Inokulasi } & $\begin{array}{c}\text { Nodula efektif } \\
\text { per tanaman }\end{array}$ & $\begin{array}{c}\text { Populasi } \\
\text { Azotobacter } \\
\left(10^{5}\right. \\
\text { CFU/mL })\end{array}$ & $\begin{array}{c}\text { N total } \\
\text { tanah } \\
(\%)\end{array}$ & $\begin{array}{c}\text { Serapan } \\
\text { (mg/tan })\end{array}$ \\
\hline Tanpa Azotobacter sp & 6,1 & 6,4 & 0,18 & $130,6 \mathrm{a}$ \\
Inokulasi pada benih & 6,8 & 8,4 & 0,21 & $154,7 \mathrm{ab}$ \\
Inokulasi pada tanah sebelum tanam & 5,4 & 9,1 & 0,21 & $150,9 \mathrm{ab}$ \\
Inokulasi pada daun & 4,4 & 1,2 & 0,19 & $190,3 \mathrm{~b}$ \\
Inokulasi pada tanah setelah tanam & 5,5 & 1,0 & 0,20 & $119,9 \mathrm{a}$ \\
\hline
\end{tabular}

Keterangan: Angka yang ditandai dengan huruf yang sama dalam satu kolom tidak berbeda nyata menurut uji Jarak Berganda Duncan pada taraf kepercayan $95 \%$. 
Tabel 2 Pengaruh metode inokulasi Azotobacter terhadap hasil dan kualitas hasil

\begin{tabular}{lccc}
\hline Metode Inokulasi & $\begin{array}{c}\text { Bobot } \\
100 \mathrm{biji} \\
(\mathrm{g})\end{array}$ & $\begin{array}{c}\text { Bobot biji } \\
\text { per petak }(\mathrm{g})\end{array}$ & $\begin{array}{c}\text { Produktivitas } \\
(\mathrm{t} / \mathrm{ha})^{*}\end{array}$ \\
\hline Tanpa Azotobacter sp & $16,2 \mathrm{bc}$ & 128.7 & 2,1 \\
Inokulasi pada benih & $15,6 \mathrm{~b}$ & 106.4 & 1,7 \\
Inokulasi pada tanah sebelum tanam & $14,8 \mathrm{ab}$ & 108.2 & 1,8 \\
Inokulasi pada daun & $17,1 \mathrm{c}$ & 88.6 & 1,4 \\
Inokulasi pada tanah setelah tanam & $14,4 \mathrm{a}$ & 69.4 & 1,2 \\
\hline Keterangan : Angka yang ditandai dengan huruf yang sama dalam satu kolom tidak berbeda nyata menurut \\
$\begin{array}{c}\text { uji Jarak Berganda Duncan pada taraf kepercayan 95 \%. } \\
\text { *Dihitung berdasarkan berat biji per petak dan luas petak. }\end{array}$
\end{tabular}

tanaman, panjang akar dan berat kering tanaman maupun serapan $\mathrm{N}$ kedelai yang diberi suspensi EPS Azotobacter di pot lebih besar daripada tanaman kontrol (Sara et al, 2014). Dilaporkan pula bahwa inokulasi dengan $R$. leguminosarum dan A. chroococcum yang meningkatkan proliferasi rhizobia di rizosfer, jumlah nodula faba bean, serapan nutrisi dan air di bawah kondisi kekurangan air di rumah kaca (Dashadi et al., 2011; Rawat et al., 2012). Pada penrcobaan ini, kemampuan isolat Azotobacter terhadap kekeringan belum teruji Hambatan utama pertanian di lahan tidak beririgasi adalah kekeringan, penelitan adaptasi diperlukan untuk mengembangkan Azotobacter yang resisten terhadap kekeringan karena secara alami Azotobacter dapat bertahan di tanah kering melalui pembentukan sista (Shirinbayan et al., 2019).

Pada percobaan ini pengendalian hama tidak optimal. Di semua petak, pada fase vegetatif penyakit bulai yang disebabkan oleh fungi Sclerospora, ulat penggulung daun Omides inidicate Kutu daun Aphis glycines menyerang daun sejak 3 MST yang akan menurunkan hasil (Marwoto et al, 2017). Kepik polong (Riportus linearis) dan penggerek polong
Etiella spp. serta penyakit bulai menyerang polong ditandai dengan lubang gerek pada polong. Hama menyerang di hampir setiap tandan polong; sekitar $80 \%$ tanaman terserang dan pemberian insentisida kurang efektif. Serangan hama dan penyakit menurunkan hasil di seluruh petak meskipun potensi produktivitasnya masih pada kisaran hasil kedelai cv. Arjasari yaitu 1,03 ton/ha-4,6 ton/ ha (Balitkabi, 2016).

\section{KESIMPULAN}

Seluruh metode aplikasi inokulan cair Azotobcter tidak meningkatkan hasil kedelai cv. Arjasari dibandingkan tanpa inokulasi tetapi produktivitas kedelai masih berada di kisaran potensi produksinya meskipun terdapat serangan hama penyakit. Percobaan ini memperlihatkan bahwa inokulasi Azotobacter yang dilakukan dengan metode penyemprotan pada daun lebih berpotensi untuk diterapkan karena meningkatkan serapan nitrogen dan bobot 100 biji kedelai. Inokulasi tambahan dengan strain Azotobacter unggul untuk meningkatkan nodulasi perlu dilakukan. 


\section{UCAPAN TERIMAKASIH}

Penelitian ini adalah bagian dari penelitian Strategis Nasional yang dibiayai oleh Dirjen Pendidikan Tinggi TA2015. Penulis berterimakasih kepada Dr. Arief Harsono dari Balai Penelitian Tanaman Kacang dan Umbi Malang yang telah menyediakan rizosfer tanaman kedelai sebagai sumber isolat Azotobacter dan Bradyrhizobium.

\section{DAFTAR PUSTAKA}

Abdurachman, A., A. Dariah, A. Mulyani. 2008. Strategi dan Teknologi Pengelolaan Lahan Kering Mendukung Pengadaan Pangan Nasional. J. Litbang, 27(2):43-39.

Adeyeye, A.S., A.O.Togun, A.B. Olaniyan, W.B. Akanbi. 2017. Effect of Fertilizer and Rhizobium Inoculation on Growth and Yield of Soyabean Variety (Glycine $\max$ L. Merrill). Adv. Crop Sci. Tech. 5(1), pp 9

Badan Pusat Statistik. 2015. Data Produksi Kedelai. www.bps.go.id [20/01/2019].

Balitkabi. 2016. Deskripsi Varietas Unggul Kedelai Kedelai 1918-2016. http:// balitkabi.litbang.pertanian.go.id/wpcontent/uploads/2016/09/kedelai.pdf

Biswas B., P.M. Gresshoff. 2014. The Role of Symbiotic Nitrogen Fixation in Sustainable Production of Biofuels. Int. J. Mol. Sci. 15:7380-7397.

Bhuiyan, D. Khanam, M.F.Hossain, M.S.Ahmed. 2008. Effect of Rhizobium Inoculation on Nodulation and Yield of Chickpea in Calcareous Soil. Bangladesh J. Agril. Res., 33(3): 549-554.
Burns Jr, T.A., P.E. Bishop, and D. W. Israel. 1981. Enhanced nodulation of leguminous plant roots by mixed cultures of Azotobacter vinelandii and Rhizobium. Plant and Soil, 62:399-412.

Dashadi, M., H. Khosravi, A. Moezzi, H. Nadian. 2011. Co-Inoculation of Rhizobium and Azotobacter on Growth Indices of Faba Bean under Water Stress in the Green House Condition. Adv. Studies Biol. 3(8):373 - 385.

Dennis, P.G., A.J. Miller, P.R. Hirsch. 2010. Are Root Exudates More Important than Other Sources of Rhizodeposits in Structuring Rhizosphere Bacterial Communities.? FEMS Microbiol. Ecol. $72: 313-327$.

Gastal, F., G. Lemaire. 2002. N Uptake and Distribution in Crops: An Agronomical and Ecophysiological Perspective. J. Exp. Bot., 53(370):789-99.

Gauri, SS., Mandal SM, Pati BR. 2012. Impact of Azotobacter Exopolysaccharides on Sustainable Agriculture. Appl. Microbiol. Biotechnol. 95(2):331-338.

Hindersah, R. 2015. Pertumbuhan dan Komposisi Eksopolisakarida Bakteri Pemfiksasi Nitrogen Azotobacter spp. pada Mediayang Mengandung Kadmium. Pros. Sem. Nas. Biodiv. Indon. 1(6):1543-1746

Kementrian Pertanian RI. 2017. Data Lima Tahun Terakhir, Tanaman Pangan Angka Tetap (Tanpang ATAP), Sub Sektor Tanaman Pangan http:// www.pertanian.go.id/home/ ?show=page $\&$ act $=$ view $\& i d=61[02 / 04 /$ 2018] 
Kukreja, K., S. Suneja, S. Goyal, N. Narula. 2004. Phytohormone Production by Azotobacter - A Review. Agric. Rev. 25 (1):70-75.

Kumalasari, I.D., E.D. Astuti, E.Prihastanti. 2013. Pembentukan bintil akar tanaman kedelai (Glycin max (L) Merrill) dengan perlakuan jerami pada masa inkubasi berbeda. J. Sains Matematika. 21(4):103-107

Lamichhane, J.R., C. Dürr, A.A. Schwanck, et al. Integrated management of damping-off diseases. A review. Agron. Sustain. Dev. (2017) 37: 10.

Lestari, S.A.D., A. Harsono. 2017. Pengaruh Pembenah Tanah dan Inokulan Rhizobium Terhadap Hasil Kedelai Pada Tanah Ultisol. Bul. Palawija, 15(1):8-14.

Marwoto, S. Hardaningsih, A. Taufiq. 2017. Hama dan Penyakit Tanaman Kedelai Identifikasi dan Pengendaliannya. Pusat Penelitian dan Pengembangan Tanaman Pangan Badan Penelitian dan Pengembangan Pertanian. Kementrian Pertanian. Bogor

Meitasari, A.D., Wicaksono, K.P. 2017. Inokulasi Rhizobium dan Perimbangan Nitrogen Pada Tanaman Kedelai (Glycine max (L) Merrill) varietas Willis. Plantropica J. Agric. Sci., 2(1)55-63.

Nagy, P.T., T. Pintér. 2015. Effects of Foliar Biofertilizer Sprays on Nutrient Uptake, Yield, and Quality Parameters of Blaufrankish (Vitis vinifera L.) Grapes, Comm. Soil Sci. Pl. Anal. 46:sup1, 219-227.
Ntambo, M.S., I. S. Chilinda, A. Taruvinga, S. Hafeez, T. Anwar, R. Sharif, C. Chambi, L. Kies. 2017. The Effect of Rhizobium Inoculation with Nitrogen Fertilizer on Growth and Yield of Soybeans (Glycine $\max$ L.). Int. J. Biosci. 10(3):163-172.

Péter Tamás Nagy \&Tamás Pintér. 2015. Effects of Foliar Biofertilizer Sprays on Nutrient Uptake, Yield, and Quality Parameters of Blaufrankish (Vitis vinifera L.) Grapes. Comm (Abstract). Soil Sci. Pl.Anal. 46, Issue Sup1:Speciel Issue of the 13th International Symposium on Soil and Plant Analysis.

Prince, S.J., B. Valliyodan, H. Ye, M. Yang, S. Tai, W. Hu, M. Murphy, L. A. Durnell, L. Song, T. Joshi, Y. Liu, J. Van de Velde, K. Vandepoele, J. G. Shannon, H. T. Nguyen. 2019. Understanding Genetic Control of Root System Architecture in Soybean: Insights into The Genetic Basis of Lateral Root Number. Plant Cell Environ., 42 (1):212-229.

Pusat Penelitian Tanah dan Agroklimat. 2000. Atlas Sumberdaya Tanah Eksplorasi Indonesia, skala 1:1.000.000. Puslittanak, Badan Litbang Pertanian, Bogor

Rawat, A.K., D.L.N. Rao, R.K. Sahu. 2012. Effect of Soybean Inoculation with Bradyrhizobium and Wheat Inoculation with Azotobacter on Their Productivity and $\mathrm{N}$ Turnover in a Vertisol. Arch. Agron. Soil Sci.12:1-13.

Sara, D.S., R. Hindersah. M. R. Setiawati. 2014. Peningkatan Populasi Bradyrhizobium di Rizosfer dan Pertumbuhan Vegetatif Kedelai Melalui 
Aplikasi Eksopolisakarida Azotobacter Prosiding Seminar Nasional MIPA 2014. 319-323.

Sharma, I. J., R.K. Samnotra, V. Kumar. 2014. Influence of Biofertilizer Application Methods and Inorganic Fertilizer on Growth, Seed yield and Economics Cost of Okra (Abelmoschus esculentus (L.) Moench) under Sub-Tropical Irrigated Area of Jammu. Int. J. Agric. Sci. 10(1):322-328.

Shirinbayan, S., H. Khosrav, M. J. Malakouti. 2019. Alleviation of drought stress in maize (Zea mays) by inoculation with Azotobacter strains isolated from semi-arid regions. Appl. Soil Ecol., 133:138-145.
Suroso, B., A. J. Sodik. 2016. Potensi Hasil dan Kontribusi Sifat Agronomi terhadap Hasil Tanaman Kedelai (Glycine max L. Merril) pada Sistem Pertanaman Monokultur. Agritrop Jurnal Ilmu-Ilmu Pertanian, 14(2):124-133

Xia, X., C. Ma, S. Dong, Y. Xu, Z. Gong. 2017. Effects of Nitrogen Concentrations on Nodulation and Nitrogenase Activity in Dual Root Systems of Soybean Plants. Soil Sci. 